Sharif University of Technology
Scientia Iranica
SCIENTIA
I RAN ICA
http://scientiairanica.sharif.edu

\title{
A review on SPT-based liquefaction potential evaluation to assess the possibility of performing a risk management
}

\author{
E. Ghorbani ${ }^{\mathrm{a}}$ and A.M. Rajabi ${ }^{\mathrm{b} *}$ \\ a. Department of Civil Engineering, University of Qom, Qom, Iran. \\ b. Department of Engineering Geology, School of Geology, College of Science, University of Tehran, Tehran, Iran. \\ Received 28 November 2017; received in revised form 20 February 2018; accepted 2 July 2018
}
KEYWORDS
Deterministic
approach;
Liquefaction;
Risk management;
SPT-based;
Residual strength.

\begin{abstract}
Liquefaction is a serious natural hazard in susceptible regions that are prone to earthquakes. According to empirical and field studies, insufficiency of liquefaction assessment methods in determining liquefaction through clays and high prediction errors has caused an unceasing new development. In this article, a comprehensive history review is presented to organize the literature on the liquefaction potential evaluation published prior to 2017. A deterministic approach based on SPT (Standard Penetration Test) records is considered to create an appropriate connection between different methods, facilitate reviewing the development of correlations in the past and current decades, assess both the cyclic stress and the flow liquefaction in a unified system, compile the latest research developments, and identify the main sources as a database for the future investigators. The study attempts to assess cyclic stress method (1971) and Chinese criteria (1982) in evaluating the liquefaction potential and to discuss the insufficiencies of these methods with reference to the liquefactions caused by the Chi-Chi (Taiwan) and Adapazari (Turkey) earthquakes in 1999. Besides, the absence of soil improvement on the basis of vulnerability and performance is identified as a research gap in this study.
\end{abstract}

(C) 2020 Sharif University of Technology. All rights reserved.

\section{Introduction}

\subsection{Deterministic approach in liquefaction potential evaluation}

Saturated loose sandy soil tends to get denser as subjected to loading. The imposed compression in this situation will be exerted on the liquid portion through the voids, which then results in water transmission to a point with lower pressure. Under cyclic quick loading,

\footnotetext{
*. Corresponding author. E-mail addresses: e.ghorbani@stu.qom.ac.ir (E. Ghorbani); amrajabi@ut.ac.ir (A.M.Rajabi)
}

pore water has no time to dissipate and, therefore, an upward pore water pressure annihilates the contact resistance between solid particles. Consequently, the overburden pressures, such as buildings' weights, will no longer be transferred to the lower earth layers. Pore water pressure annihilates the contact resistance between solid particles and causes liquefaction. As residual pore water pressure lasts a longer time by comparing with transient pore water pressure, it has a major effect on soil strength and stiffness [1]. The upward transmission of pore water due to liquefaction in a deep layer of soil may cause liquefaction in upper layers [2]. As liquefaction occurs, a resultant consolidation follows in the soil mass, which will cause soil densification that may be accompanied by ground 
settlements [2]. A simplified procedure is defined for liquefaction-induced building settlement on the basis of earthquake-induced shear strain potential [3].

Earthquake-induced shear stress in liquefied soil is defined by Seed and Idriss [4] as Cyclic Stress Ratio (CSR). By propagating the seismic waves, soil will not behave as a rigid body and, therefore, the resultant shear stress in any depth is less than the values calculated by Eq. (1). To reduce the shear stress with depth, $r_{d}$ as the depth reduction factor is included in Eq. (2). $r_{d}$ is defined as the maximum shear stress in reality divided by the maximum shear stress in rigid body (Eq. (3)). Then, a coefficient of 0.65 is applied to define the equivalent shear stress and to reduce the peak cyclic stress that occurs only once (Eq. (4)) [5].

$$
\begin{aligned}
& \tau_{\max (\text { rigid body })}=\gamma \cdot h \frac{a_{\max }}{g}, \\
& \tau_{\max (\text { real })}=\gamma \cdot h \frac{a_{\max }}{g} \cdot r_{d}, \\
& r_{d}=\frac{\tau_{\max (\text { real })}}{\tau_{\max (\text { rigid body })}} \\
& \tau_{e q}=0.65 \gamma \cdot h \frac{a_{\max }}{g} \cdot r_{d},
\end{aligned}
$$

where $\gamma$ is the total unit weight of the soil, $h$ is the depth of the soil layer, $a_{\max }$ is the maximum horizontal acceleration on the ground surface, $g$ is the acceleration of gravity, $r_{d}$ is the depth reduction factor, and $\tau_{e q}$ is the equivalent earthquake shear stress. On the other hand, the resistance of the soil against liquefaction is expressed by Cyclic Resistance Ratio (CRR), which is identified by field tests like Standard Penetration Test (SPT).

The simplified and semi-empirical method of cyclic stress developed by Seed and Idriss [4] has been recommended for level ground conditions, low static shear stress, and effective overburden stress in the range of $100 \mathrm{kPa}$. Therefore, the following correction factors are applied to the correlations (Eq. (5)) and the factor of safety is defined in Eq. (6):

$$
\begin{aligned}
& C R R=C R R_{\sigma=1, \alpha=o} \cdot K_{\alpha} \cdot K_{\sigma}, \\
& F S=\frac{C R R \times K_{\sigma} \times K_{\alpha}}{C S R},
\end{aligned}
$$

where $K_{\alpha}$ is the static shear stress correction factor, and $K_{\sigma}$ is the overburden stress correction factor. The best definition to evaluate liquefaction potential considering cyclic stress method prior to 2000 is presented in Figure 1. In another approach to assessing liquefaction potential, Seed and Idriss [6] presented their findings in the form of three criteria (Eqs. (7)-(9); Figure 2) known later as the Chinese criteria. If the soil fulfills these criteria, then it is vulnerable to liquefaction. Accordingly, the authors denied any probability of liquefaction in clays.

Percent finer than $0.005 \mathrm{~mm} \leq 15 \%$,

Liquid Limit $(L L) \leq 35 \%$,

Water content $\left(w_{n}\right) \geq 0.9 \times L L$.

Andrews and Martin [7] refined the Chinese criteria based on different definitions of liquid limit and clay content between China and the United States. Actually, they maintained that a liquid limit of 35 with the fall cone penetrometer corresponds to a liquid limit of 32 with the Casagrande-type apparatus. In addition, in China, the clay content is defined as particles finer than $0.005 \mathrm{~mm}$, while, in the United States, it is defined as particles finer than $0.002 \mathrm{~mm}$. Andrews and Martin [7] removed water content from their criteria and maintained clay content and liquid limit as the key soil parameters, considering plastic or non-plastic behavior of fines (Table 1). In addition, Bray et al. [8] claimed that the effective factor in assessing the liquefaction potential was the mineral-clay particle, not the clay-sized particle.

The inconsistency of the developed procedure in predicting liquefaction induced by the 1999 Adapazari (7.6) and 1999 Chi-Chi (7.6) earthquakes in regions with a high percentage of fines content has encouraged researchers to reconsider the correlations. The

Table 1. Refined Chines criteria considering liquefaction in fine-grained soils [7].

\begin{tabular}{ccc}
\hline Features & \multicolumn{1}{c}{$\boldsymbol{L}<\mathbf{3 2}$} & \multicolumn{1}{c}{$\boldsymbol{L} \boldsymbol{L} \geq \mathbf{3 2}$} \\
\hline Clay content $<10 \%$ & \multicolumn{1}{c}{ Susceptible } & $\begin{array}{l}\text { Further studies required } \\
(\text { considering plastic non-clay } \\
\text { sized grains such as Mica) }\end{array}$ \\
& $\begin{array}{l}\text { Further studies required } \\
\text { (considering non-plastic clay sized } \\
\text { Clay content } \geq 10 \%\end{array}$ & $\begin{array}{c}\text { Not susceptible } \\
\text { tailings })\end{array}$ \\
\hline
\end{tabular}




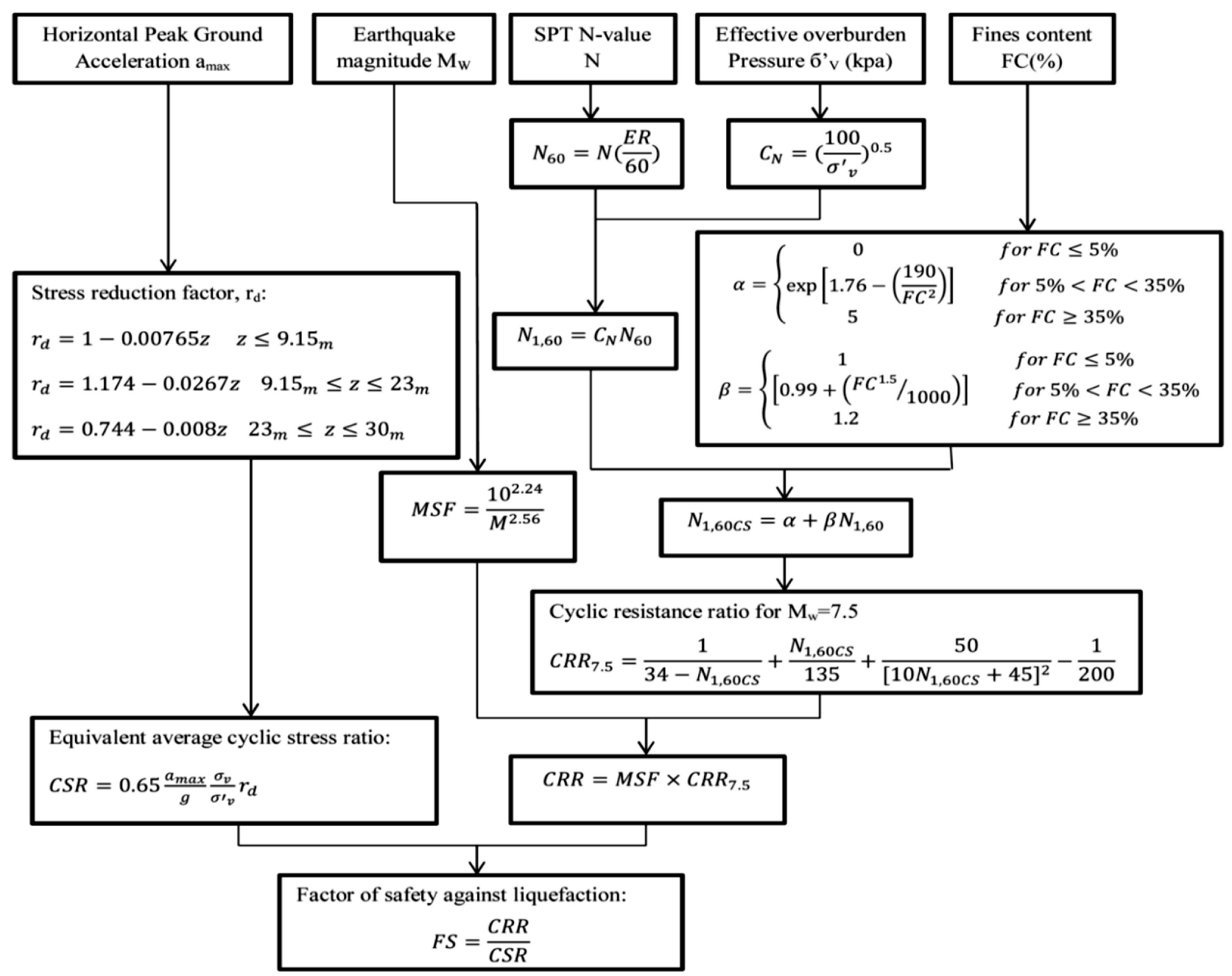

Figure 1. Evaluation of liquefaction potential prior to 2000 considering cyclic stress method defined [4].

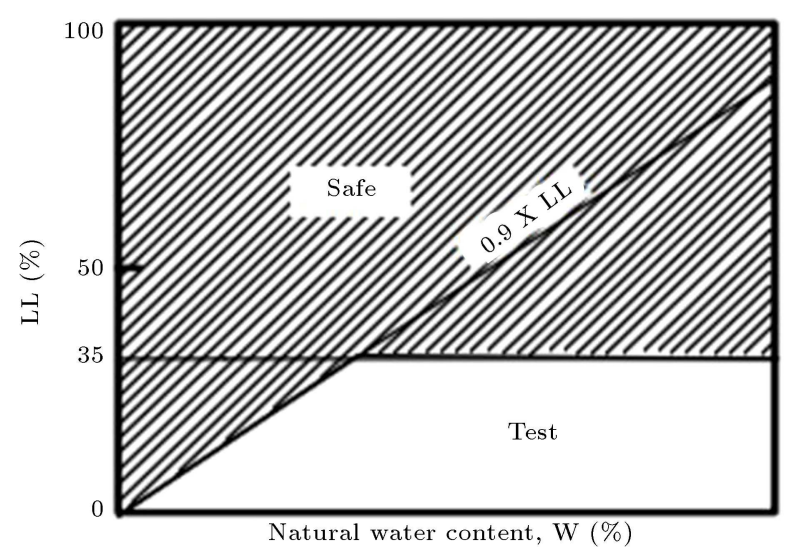

Figure 2. Chinese criteria [6].

insufficiencies of the aforementioned methods will be discussed exhaustively in Section 1.2.

\subsection{The 1999 earthquakes of Adapazari (7.6) in Turkey and Chi-Chi (7.6) in Taiwan}

The 1999 Adapazari (Turkey) earthquake (7.6) has caused extensive liquefaction. Typical concrete frame buildings with 3 to 5 stories form the general configuration of the city of Adapazari. This city is located over deep alluvial sediments with fines content over $35 \%$ containing non-plastic silts, silty sands, and clays with the bedrock exceeding the depth of $200 \mathrm{~m}$. It was observed that free fields far from the residential regions were less prone to liquefaction, while the regions with tall and heavy buildings were much more susceptible to liquefaction [9]. Therefore, the influence of static shear stress resultant of the existence of an overburden is emphasized.

Chu et al. [10] declined the Chinese criteria analyses using three examples based on the investigations implemented after the 1999 Chi-Chi (Taiwan) earthquake (7.6). According to the Chinese criteria, if $L L<35 \%, w_{n} / L L>0.9$ and the field tests confirm the presence of loose soil, then the soil is liquefiable. On the basis of Chinese criteria, liquefaction was expected to occur in the case of Wufang; however, there was no evidence of ground failure within this zone. Thus, this 
sample is inconsistent with Chinese criteria. Therefore, it strengthens the hypothesis that the effects of static shear stress should be emphasized while involving high fines content and marginal plastic soils.

Chang et al. [11] assessed 1500 borehole logs obtained from 1999 Chi-Chi (Taiwan) earthquake (7.6) to evaluate the three different methods of Seed et al. (2001), Tokymatsu and Yushimi (1983) [12], and New version of Japan's Road Association (NJRA, 1996) [11]. The statistical results indicate that the most accurate methods for estimating the occurrence or nonoccurrence of liquefaction are those proposed by Tokymatsu and Yushimi (1983) [12], NCEER workshop [13], and then Japan Rail Association (JRA) (1996) [14] with prediction errors of $13.3 \%, 14.6 \%$, and $14.8 \%$, respectively. According to these high prediction errors, Chang et al. [11] concluded that none of the aforementioned methods till 2001 were reliable enough yet to be confidently used.

As discussed above, the 1999 Chi-Chi (7.6) and the 1999 Adapazari (7.6) earthquakes caused extensive liquefaction in spite of the significant fines content. In addition, the evaluations presented by Chang et al. [11] indicate that the percentage of the prediction errors in existing methods is not admissible.

A workshop was executed in Los Angeles in 2003 by Seed et al. in order to evaluate the existing methods and apply the required corrections [15]. In this workshop, the triggering reasons of liquefaction were divided into two categories:

(i) Cyclic stress-induced liquefactions, known as classic liquefaction or cyclic liquefaction;

(ii) Static shear stress or monotonic shearing-induced liquefaction, which is known as strain-softening.

Strain-softening has also been named as "Sensitivity" [15].

The strain-softening is possible even in plastic silts and clays; the behavior of soils of higher plasticity, which do not appear to be prone to cyclic liquefaction, is gradual rather than abrupt. In fact, soils of higher plasticity may also experience loss of strength and stiffness; however, this strength loss is gradual, with lower pore pressure generation and larger shear strains. In fact, as the plasticity of soil increases, the soil behavior will be controlled by plastic fines content; accordingly, ductility of soil will be increased directly with the increase of fines content. Therefore, the failure occurs at larger shear strain. As a result, one of the modified Chinese criteria conditions, i.e., clay content, has been clearly breached [15]. Liquefactioninduced settlement of a clay layer was discussed by Sato et al. [16]. Another similar phenomenon to strainsoftening is flow liquefaction. The special characteristic for which flow liquefaction is known is the distant liquefied materials, carried after liquefaction. This characteristic has been noticed in many studies before [17-20]. Casagrande [17] denoted the flow liquefaction potential with the Critical Void Ratio (CVR) line, which was later refined by Castro [18] as Steady State Line (SSL) (Figure 3) [17,18]. Accordingly, the soils on the upper side of the CVR or SSL are prone to flow liquefaction $[17,18]$. According to Robertson and Wride [20], both static and dynamic loading may trigger the flow liquefaction. Due to the continuous nature of flow liquefaction, the movements may continue even after the cyclic loading [19]. A new empirical curve is also defined by Javanmardi et al. [21] that can be progressive.

Seed et al. [15] divided the PI-LL chart into three parts as illustrated in Figure 4. Zone A is susceptible

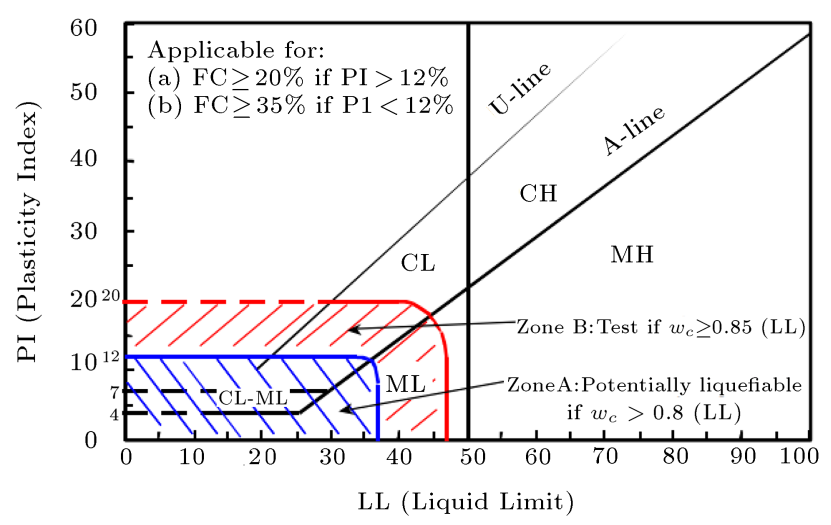

Figure 4. Liquefaction assessment regarding the PI-LL zonation [15].

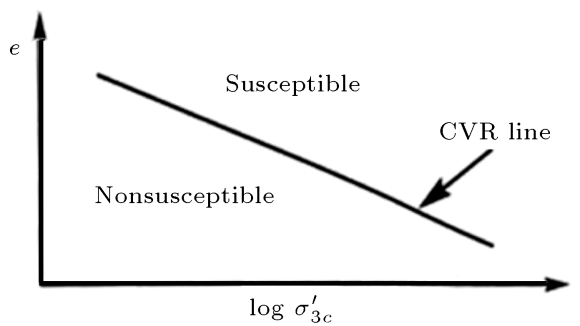

(a)

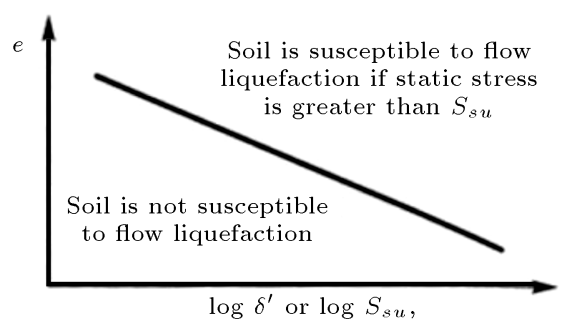

(b)

Figure 3. (a) Critical Void Ratio (CVR) line defined by Casagrande [17]. (b) Steady State Line (SSL) line defined by Castro [18]. 


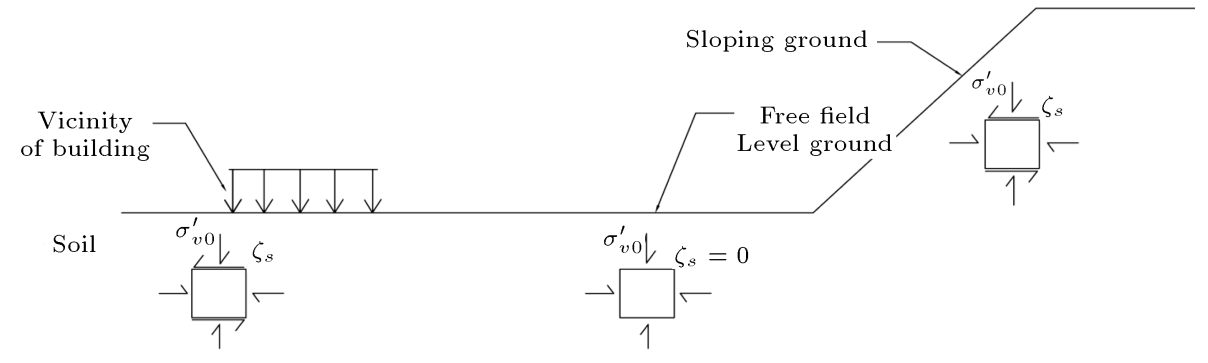

Figure 5. Soil initial condition while subjected to static shear stress.

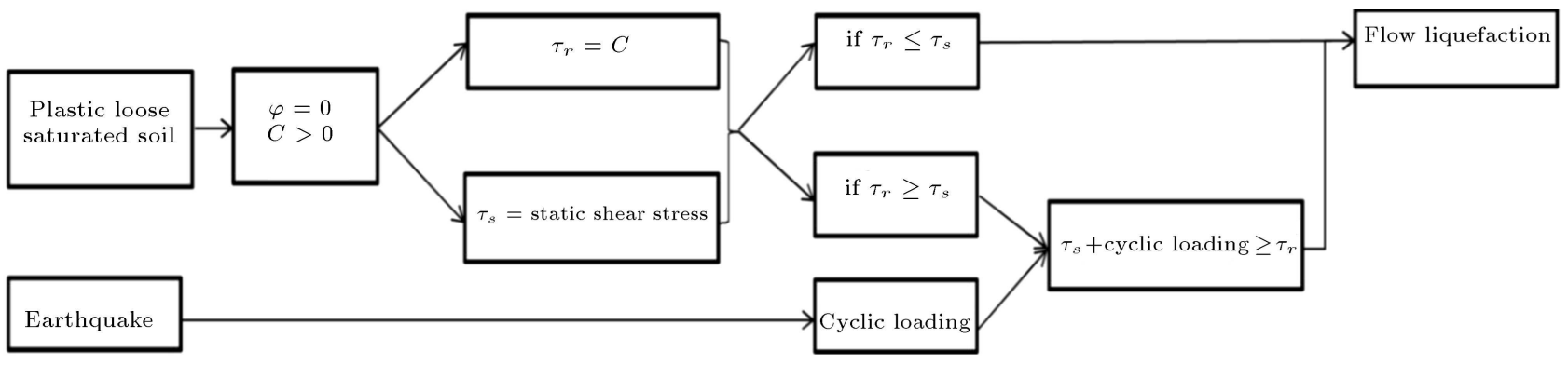

Figure 6. Flow liquefaction mechanism in plastic loose saturated soils.

to cyclic liquefaction potentially, Zone B is potentially liquefiable, and Zone $\mathrm{C}$ (the area out of Zones $\mathrm{A}$ and $\mathrm{B}$ ) is not prone to cyclic liquefaction due to high plasticity; the latter, however, should be checked for the strainsoftening. Soil in this zone is vulnerable to strength loss with remolding or large shear displacements. This behavior may extend to Zone B. These soils may be liquefiable only if they are subjected to cyclic and static shear stresses simultaneously, while they are harmless in the absence of static shear stresses [15]. Nonplastic silty soils or clayey silts containing high water content relative to their liquid limit are among the most dangerous of liquefiable soils [15].

The initial stress condition is important in assessing the liquefaction potential. As illustrated in Figure 5, soil conditions in a free field are different from the states subjected to shear stress beneath a building or a sloping ground. Static shear stress in loose soil increases the vulnerability, while, in a very dense soil, it strengthens the soil against liquefaction due to soil dilative behavior. In other words, pore water pressure dissipation due to dilation in a dense soil strengthens the soil against liquefaction [15]. Briefly, building construction in a loose soil reduces the strength; however, in a dense soil, it strengthens the soil against liquefaction.

In brief, as static shear stress exceeds the strength of a loose saturated soil containing high clay minerals, in a situation in which the soil is simultaneously subjected to cyclic stress, an upward pore water pressure will annihilate the contact and cohesive resistance of the soil and, therefore, even a plastic silty soil will gradually liquefy (Figure 6). According to the above discussion, the liquefactions occurred on natural slopes and overburdened grounds in 1999 Chi-Chi (Taiwan) and 1999 Adapazari (Turkey) earthquakes are legitimized.

The manuscript continues as follows: the effective parameters in deterministic approach and residual shear strength after liquefaction are reviewed in Section 2, titled method; the possibility of performing a performance-based soil improvement is discussed in Section 3; finally, the summary and conclusions are pointed out in Section 4.

\section{Method}

In 1997, a workshop sponsored by National Center for Earthquake Engineering Research (NCEER) was convened by T.L. Youd and I.M. Idriss to review the recent developments in correlations defined for liquefaction assessment [13]. In this section, we will review the new developments on cyclic stress method and the parameters after the 1997 workshop [13]. The review in this section is organized so as to evaluate the possibility of reaching a risk management on the basis of studies and developments in different parameters, involved in the liquefaction assessment correlations. This section is formed in three subtitles: developments in effective parameters in deterministic approach, correlations between different field tests, and residual shear strength after liquefaction.

\subsection{Effective parameters in deterministic approach and recent developments in liquefaction potential evaluation}

As described, cyclic stress method in liquefaction potential evaluation has been developed by many experts 
Table 2. Standard Penetration Test (SPT) calibration coefficients [13].

\begin{tabular}{lccc}
\hline \multicolumn{1}{c}{ Factor } & Equipment variable & Term & Correction \\
\hline Overburden pressure & - & $C_{N}$ & $\left(\frac{P_{a}}{\sigma_{v 0}^{\prime}}\right)^{0.5 *}$ \\
Overburden pressure & - & $C_{N}$ & $C_{N} \leq 1.7$ \\
Energy ratio & Donut hammer & $C_{E}$ & $0.5-1.0$ \\
Energy ratio & Safety hammer & $C_{E}$ & $0.7-1.2$ \\
Energy ratio & Automatic-trip & $C_{E}$ & $0.8-1.3$ \\
Borehole diameter & Donut-type hammer & & \\
Borehole diameter & $65-115 \mathrm{~mm}$ & $C_{B}$ & 1.0 \\
Borehole diameter & $150 \mathrm{~mm}$ & $C_{B}$ & 1.05 \\
Rod length & $200 \mathrm{~mm}$ & $C_{B}$ & 1.15 \\
Rod length & $<3 \mathrm{~m}$ & $C_{R}$ & 0.75 \\
Rod length & $3-4 \mathrm{~m}$ & $C_{R}$ & 0.8 \\
Rod length & $4-6 \mathrm{~m}$ & $C_{R}$ & 0.85 \\
Rod length & $6-10 \mathrm{~m}$ & $C_{R}$ & 0.95 \\
Sampling method & $10-30 \mathrm{~m}$ & $C_{R}$ & 1.0 \\
Sampling method & Standard sampler & $C_{S}$ & 1.0 \\
$* P_{a}$ is the reference effective overburden pressure of $100 \mathrm{kPa}$, and $\sigma_{v 0}^{\prime}$ is \\
the existing effective overburden pressure. & & \\
& & &
\end{tabular}

in recent decades $[4,5,13,15,22-25]$. One of the usual methods for evaluating the in-situ soil strength in cyclic stress method is SPT field test that should be integrated with calibration coefficients. In this section, the recent corrections over these coefficients and the controversial parameters of $K_{\sigma}, K_{\alpha}, r_{d}$, and Magnitude Scaling Factor (MSF) will be discussed in SPT-based correlations.

\subsubsection{SPT calibration coefficients}

One of the usual methods for evaluating the soil shear resistance against liquefaction is using SPT field test results. The $N$ value, which is the measured SPT blow counts, should be calibrated using the coefficients represented in Eq. (10) [13]:

$$
N_{1,60}=N \cdot C_{N} \cdot C_{E} \cdot C_{B} \cdot C_{R} \cdot C_{S},
$$

where $N$ is the measured SPT blow counts, $C_{N}$ is the factor in normalizing blow counts to a reference effective overburden stress, $C_{E}$ is the correction for the hammer energy ratio to an equivalent value of $60 \%$, and $C_{B}, C_{R}$, and $C_{S}$ are correction factors for borehole diameter, rod length, and sampler type, respectively.

The 1997 workshop listed the parameters and the corrections over the coefficients as in Table 2.

For an overburden less than $200 \mathrm{kPa}$, NCEER workshop recommended using Eq. (11) and, for higher values, $C_{N}$ is calculated using Eq. (12). In addition, $C_{N}$ should not exceed a value of 1.7 .

$$
C_{N}=\left(\frac{P_{a}}{\sigma_{v 0}^{\prime}}\right)^{0.5} \quad \sigma_{v 0}^{\prime}<200 \mathrm{kPa},
$$

$$
C_{N}=\frac{2.2}{1.2+\frac{\sigma_{v 0}^{\prime}}{P_{a}}} \quad \sigma_{v 0}^{\prime}>200 \mathrm{kPa} .
$$

$P_{a}$ is the reference effective overburden pressure of $100 \mathrm{kPa}$, and $\sigma_{v 0}^{\prime}$ is the existing effective overburden pressure.

Boulanger [26] introduced a new correlation for $C_{N}$, which was refined by Boulanger and Idriss [27] and was lastly confirmed as Eq. (13) by Idriss and Boulanger [25]:

$$
\begin{gathered}
C_{N}=\left(\frac{P_{a}}{\sigma_{v 0}^{\prime}}\right)^{\alpha} \leq 1.7, \quad \alpha=0.784-0.0768 \sqrt{N_{1,60}} \\
N_{1,60} \leq 46
\end{gathered}
$$

where $N_{1,60}$ is the calibrated $N$ in SPT test. Eq. (13) needs an iterative process to be solved since $C_{N}$ is dependent on $N_{1,60}$, which is dependent on $C_{N}$. In Eq. (13), $C_{N}$ is limited to 1.7. The $C_{R}$ parameter is illustrated in Figure 7 [15]. In addition, the $C_{S}$ correction is applied if the standard sampler is not used. The application of the untypical sampler without liners causes shaft friction reduction that reduces the penetration resistance; thus, an increasing multiplier of $C_{S}$ in the range of 1.1 to 1.3 is applied (Eq. (14)) [15]:

$$
1.1 \leq C_{S}=1+\frac{N_{1,60}}{100} \leq 1.3
$$

2.1.2. Influence of fines content in SPT results The measured $N$ should be calibrated for different 


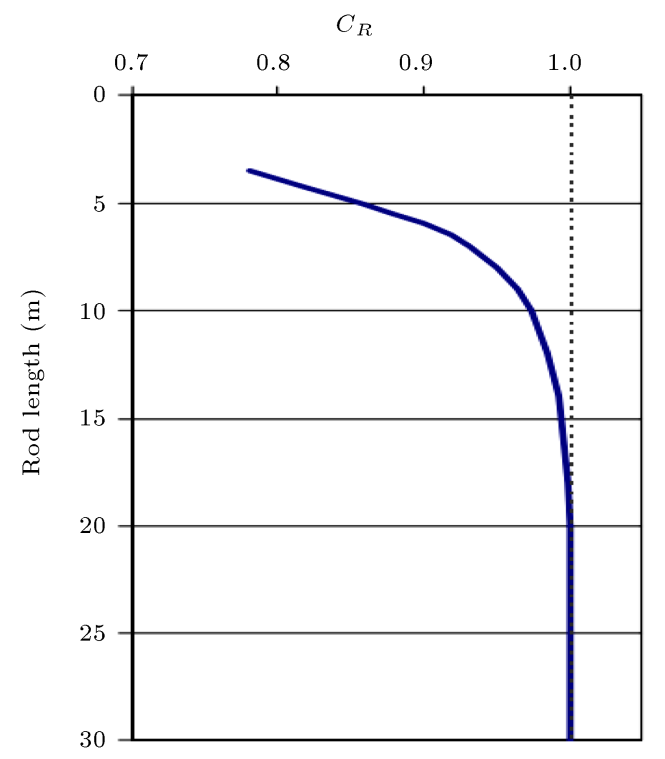

Figure 7. The correction for rod length [15].

percentages of fines content, as indicated by many researchers $[5,13,15,25,28]$. Seed et al. [28] found changes in SPT results for different fines content. The equations for different fines content have been gradually developed since 1985, and Eqs. (15)-(17) were confirmed in the 1997 workshop [13]:

$$
\begin{aligned}
& N_{1,60 c s}=\alpha+\beta\left(N_{1,60}\right), \\
& \alpha=0 \text { for } F C \leq 5 \%, \\
& \alpha=\exp \left[1.76-\left(\frac{190}{F C^{2}}\right)\right] \text { for } 5 \%<\mathrm{FC}<35 \% \\
& \alpha=5 \text { for } F C \geq 35 \%, \\
& \beta=1 \text { for } F C \leq 5 \%, \\
& \beta=\left[0.99+\left(\frac{F C^{1.5}}{1000}\right)\right] \text { for } 5 \%<F C<35 \% \\
& \beta=1.2 \text { for } F C \geq 35 \%,
\end{aligned}
$$

where $F C$ is fines content, $\alpha$ and $\beta$ are the fines content calibration factors, and $N_{1,60 c s}$ is the calibrated SPT-N for SPT coefficients and fines content.

A new correlation was introduced for different fines content using a probabilistic method on the basis of an inclusive database (Eqs. (18) and (19)) [15]:

$$
\begin{aligned}
& N_{1,60 c s}=N_{1,60} \times C_{\text {fines }}, \\
& C_{\text {fines }}=(1+0.004 \times F C)+0.05 \times\left(\frac{F C}{N_{1,60}}\right),
\end{aligned}
$$

where $C_{\text {fines }}$ is the $F C$ calibration factor, $F C=0$ for $F C \leq 5 \%$, and $F C=35$ for $F C \geq 35 \%$.
In Eq. (18), there is an increase in 6.5 blow counts for $F C=35 \%$, while, for a similar $\mathrm{FC}$, in Eq. (15), there is an increase in 10 blow counts in SPT-N. Based on empirical studies, some deviation was discerned in developed correlations considering plastic characteristics of fines [25]. Therefore, Eq. (20) was presented to account for SPT-N increase in non-plastic soils and soils with low plasticity $(P I<7)$.

$$
N_{1,60 c s}=N_{1,60}+\Delta\left(N_{1,60}\right)
$$

where:

$$
\Delta\left(N_{1,60}\right)=\exp \left[1.63+\frac{9.7}{F C+0.1}-\left(\frac{15.7}{F C+0.1}\right)^{2}\right]_{(21)}
$$

Considering clay minerals in soils, Plasticity Index (PI) is a key parameter used to determine fines influence. $P I=7$ was defined as the boundary of plastic and non-plastic soils [27]. The correlation of Eq. (20) is only applicable in soils with $P I<7$ (see Gratchev et al. $[29,30]$ for more information).

\subsubsection{CRR of soil on the basis of SPT data}

In order to determine the CRR of a soil, field investigation is required. For this purpose, the typical field tests are SPT, CPT, BPT, and $V_{S}$. In this section, the SPT-based correlations for defined for soil shear resistance are reviewed. As recommended by NCEER workshop, CRR of a soil subjected to liquefaction is obtained using Eq. (22). Of note, according to NCEER workshop, soil with $N$ values greater than 30 is determined as non-liquefiable [13].

$$
\begin{aligned}
C R R_{7.5}= & \frac{1}{34-N_{1,60 c s}}+\frac{N_{1,60 c s}}{135} \\
& +\frac{50}{\left[10 N_{1,60 c s}+45\right]^{2}}-\frac{1}{200},
\end{aligned}
$$

where $N_{1,60 c s}$ is the calibrated SPT-N for SPT coefficients and fines content.

Another correlation is developed that estimates CRR for non-plastic soil with $P I<7$ as represented in Eq. (23) [25].

$$
\begin{aligned}
C R R= & \exp \left[\frac{N_{1,60 c s}}{14.1}+\left(\frac{N_{1,60 c s}}{126}\right)^{2}\right. \\
& \left.-\left(\frac{N_{1,60 c s}}{23.6}\right)^{3}+\left(\frac{N_{1,60 c s}}{25.4}\right)^{4}-2.8\right] .
\end{aligned}
$$

\subsubsection{Adjusting soil shear resistance for static shear stress}

As discussed earlier, the procedure described by Seed and Idriss [4] was developed for level to gently sloping 


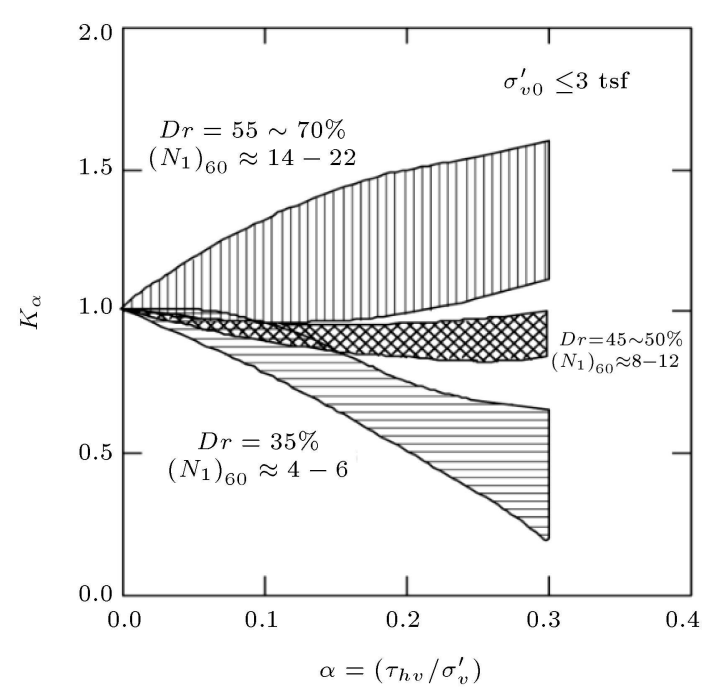

Figure 8. $K_{\alpha}$ for different values of density and static shear stress [15].

sites, referred to as a low static shear stress. Seed [31] defined a static shear stress factor $\left(K_{\alpha}\right)$ that affected the soil resistance against liquefaction, and it was applied to account for density of soil. This factor and the theory behind it were noticed in 1997 workshop; however, no equations had been proposed to account for this factor due to the lack of convergence in past studies. Seed et al. [15] presented a chart to illustrate how $K_{\alpha}$ affects characteristics of loose and dense soils subjected to static shear stress. As illustrated in Figure 8, for loose soils with low SPT-N values, an increase in $\alpha$ decreases $K_{\alpha}$; inversely, for dense soils with high SPT-N values, an increase in $\alpha$ increases $K_{\alpha}$. The parameter $\alpha$ is the ratio of local static shear stress to effective overburden pressure; the static shear stress is indicated with $\tau_{h v}$ in Figure 8. In addition, ranges of loose and dense soils are illustrated in this figure. As represented in Eq. (24), to account for the equivalent cyclic shear stress as $\mathrm{CSR}_{e q}$, the CSR is divided by $K_{\alpha}$. Therefore, as noticed before, building construction in loose soil decreases soil resistance, while, in dense soil, it strengthens the sand against liquefaction. These conditions are valid as long as effective overburden pressure is less than $300 \mathrm{kPa}[15]$.

$$
C S R_{e q}(\alpha>0)=\frac{C S R(\alpha=0)}{K_{\alpha}} .
$$

\subsubsection{Adjusting soil shear resistance for high overburden stress $\left(K_{\sigma}\right)$}

The procedure described by Seed and Idriss [4] was developed for low effective overburden stress in the range of $100 \mathrm{kPa}$. Seed [31] presented the decreasing parameter of $K_{\sigma}$ in the form of a chart, which was developed by many experts through decades [5,13,15,23,31-33]. As the overburden stress increases $100 \mathrm{kPa}$, dilation potential of soils and the associated resistance re-

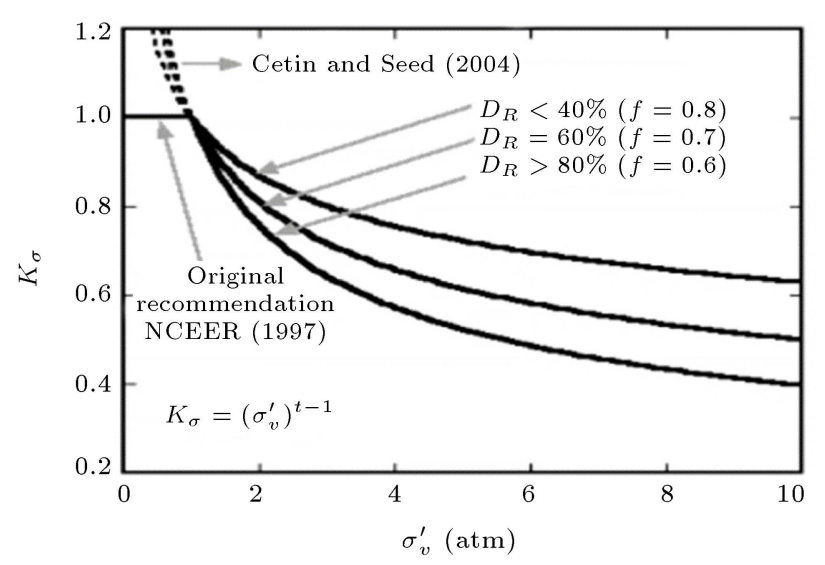

Figure 9. Correction factor of $K_{\sigma}$ for different values of effective overburden stress attained from NCEER (1997) [13] and Cetin and Seed [5].

duces. Actually, as the confining pressure oversteps, soil resistance against liquefaction decreases; therefore, the correction factor of $K_{\sigma}$ is necessary to account for high overburden stress [33]. NCEER workshop determined the upper limit of 1 for $K_{\sigma}$ regarding the former studies [13]. According to Seed et al. [15], the value of $K_{\sigma}$ is extended to 1.5 on the surface; however, in more conservative approaches (e.g. dictated by the lack of sufficient data), it is recommended that the previous conclusions inferred from 1997 workshop be used. An increase in effective overburden stress leads to an increase in liquefaction potential under a similar CSR, which is defined by Eqs. (25) and (26) and illustrated in Figure 9 [5]:

$$
\begin{aligned}
& C R R_{e q}=C R R_{1 a t m} \times K_{\sigma} \\
& K_{\sigma}=\left(\sigma_{v}^{\prime}\right)^{f-1}
\end{aligned}
$$

where $C R R_{e q}$ is the equivalent $C R R$, calibrated for high overburden stress, $\sigma_{v}^{\prime}$ is the effective overburden pressure, and $f$ is a function of $N_{1,60 c s}\left(N_{1,60 c s}\right.$ represents blow counts varying between 5 to 40 ). The parameter $f$ is in $0.6 \sim 0.8$ range. Boulanger [26] defined a coefficient, $\xi_{R}$, to account for the simultaneous effect of the existing relative density and effective overburden stress on CRR (see [26] for more information).

Figure 10 compares the results studied by Idriss and Boulanger [25] and Hynes et al. [23] for the $K_{\sigma}$ parameter. According to Figure 11, $K_{\sigma}=1$ is recommended for the upper limit.

\subsubsection{Magnitude Scaling Factor (MSF)}

The most important factors in liquefaction potential evaluation in the cyclic stress method are earthquake magnitude and Peak Ground Acceleration (PGA). In order to account for these two important factors, MSF and $r_{d}$ are used to adjust earthquake magnitude and PGA in the calculations. In recent years, an 


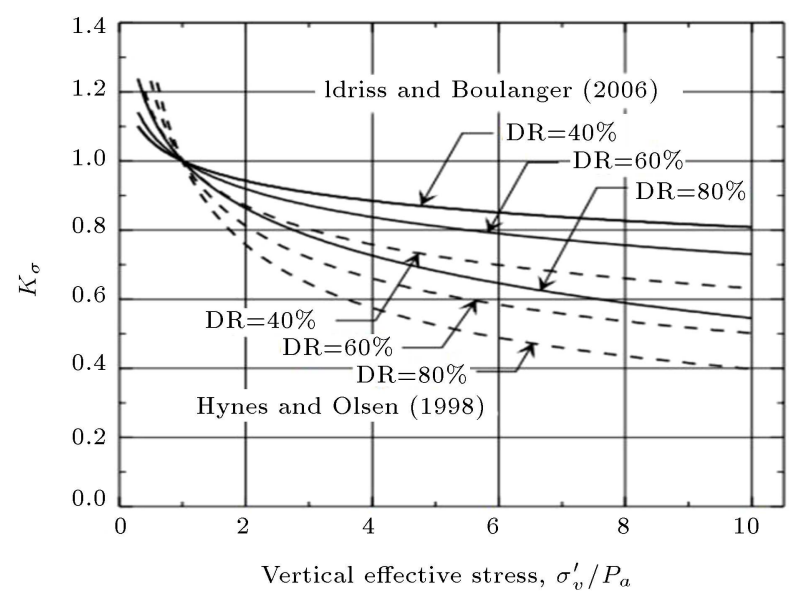

Figure 10. Correction factor of $K_{\sigma}$ for different values of effective overburden stress attained from Hynes et al. [23] and Idriss and Boulanger [25].

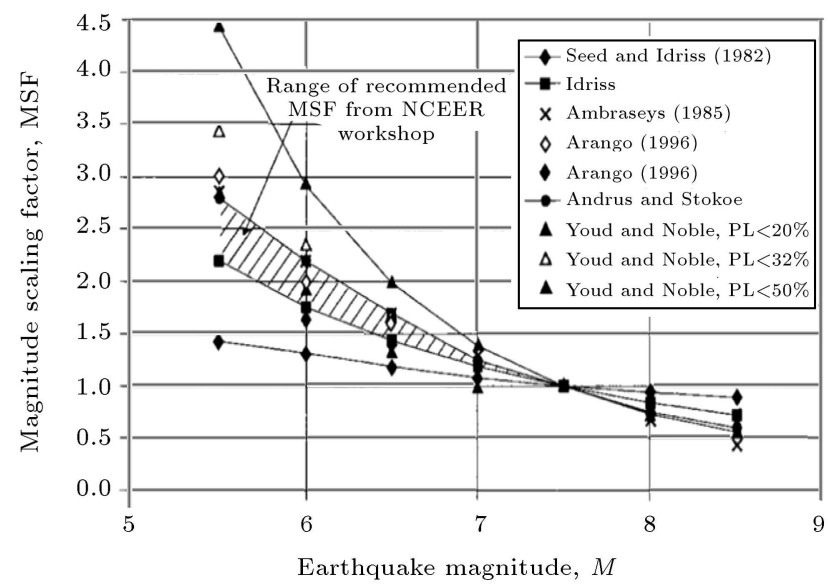

Figure 11. Magnitude Scaling Factor (MSF) defined by different researchers [13].

attempt has been made to correlate the MSF with soil characteristics besides the seismic parameters [25,3436]. According to NCEER workshop, for seismic magnitudes lower than 7.5, MSF was recommended as the average of the proposed value by Idriss as a personal communication to Youd in 1995 and Andrus and Stokoe [22] proposed Eq. (28); however, due to lack of sufficient data for higher seismic magnitudes, the former values proposed by Idriss in 1995 were suggested (Eq. (27) and Figure 11) [13,22].

$$
M S F_{\text {ave }}= \begin{cases}\frac{M S F_{\text {Andrus }-S t o k e}+M S F_{\text {Idriss }}}{2} & M \leq 7.5 \\ M S F_{\text {Idriss }} & M>7.5\end{cases}
$$

where:

$$
M S F_{\text {Andrus-Stoke }}=\left[\frac{M}{7.5}\right]^{-2.56},
$$

and:

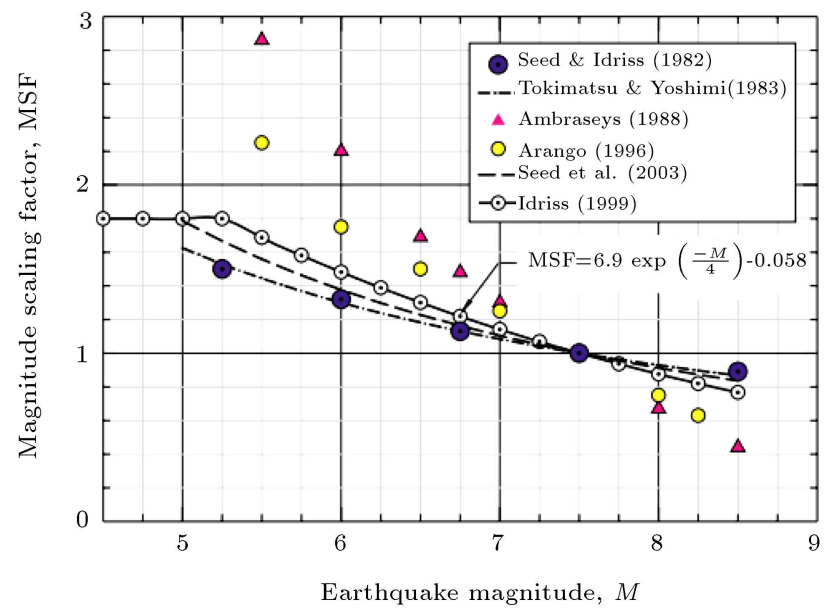

Figure 12. Comparison of Magnitude Scaling Factor (MSF) attained by different researchers [25].

$$
M S F_{\text {Idriss }}=\frac{10^{2.24}}{M^{2.56}}
$$

where $M$ is the earthquake magnitude. A correlation was recommended to the 1997 workshop by Idriss in 1999 (personal communication to NCEER, 1997) for MSF (Eq. (30)), which was almost convergent with the later studies of Seed et al. [15] as illustrated in Figure 12 $[15,13]$.

$$
M S F=6.9 \exp \left(\frac{-M}{4}\right)-0.058 \leq 1.8 .
$$

Probabilistic studies indicated that MSF for different values of $M$ is lower than that reported by NCEER and almost equal to the Idriss recommendation in 1999 (personal communication to NCEER, 1997) [5]. Convergence in MSF attained from the experimental studies by Idriss in 1999 and probabilistic studies by Cetin et al. [5] is expressive.

Consequently, since $r_{d}$ and MSF are both dependent on the earthquake magnitude $(M)$ simultaneously, the corresponding MSF and $r_{d}$ should be applied in cyclic stress method correlations (earthquake magnitude-dependent $r_{d}$ will be discussed in the following Section 2.1.7). Correlating MSF with soil characteristics is a great step forward, which was taken in 2006; the traditional MSF was developed only for clean sands. Idriss and Boulanger [25] denoted a loglog relationship that correlates loading cycles $(N)$ with soil characteristics (b) and CRR (Eq. (31)):

$$
C R R=a \cdot N^{-b}
$$

where $b$ is the negative slope of the relationship between CRR and loading cycles $(N)$ related to soil characteristics and is derived by laboratory experiments, and the parameter $a$ is a fitting coefficient. Experimental studies were implemented in order to define new MSF, which is dependent on soil characteristics by means 


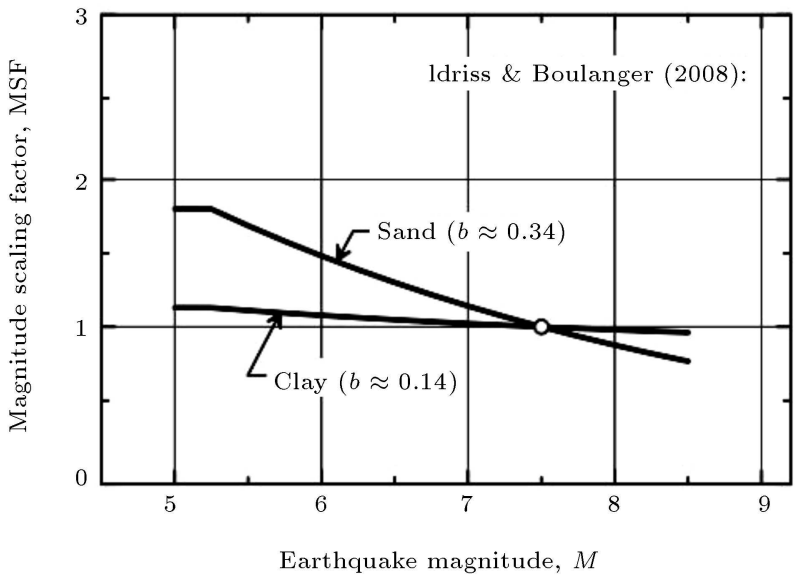

(a)

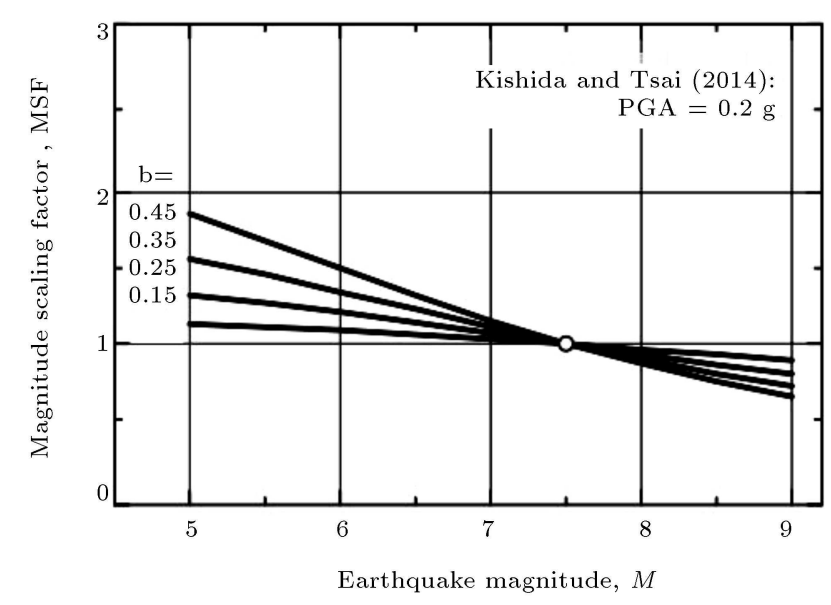

(b)

Figure 13. Magnitude Scaling Factor (MSF) for different values of $b$ and $M$ : (a) Idriss and Boulanger [37] and (b) Kishida and Tsai [35].

of $b$ parameter (Figure 13(a)) [37]. In these studies, (b) is obtained from cyclic loading in clays and plastic silts considering soil-softening behavior. Kishida and Tsai [35] developed the new MSF for wider ranges of $b$ as illustrated in Figure 13(b). An increase in over consolidation ratio implies greater soil density and, as soil density increases, a greater value of $b$ will be derived from laboratory tests [38].

MSF is affected by many factors through seismic parameters and soil characteristics; correlating all the influential factors is impractical. Although Boulanger and Idriss [36] developed MSF correlations for different values of fines content and different soil types (Eq. (32)).

$$
M S F=1+\left(M S F_{\max }-1\right)\left[8.64 \exp \left(\frac{-M}{4}\right)-1.325\right] .
$$

The parameter $M S F_{\max }$ indicates different values of $b$ and is attained from $N_{1,60 \mathrm{cs}}$ as Eq. (33) clarifies [36]. $M S F_{\max }$ is 1.8 and 1.09 for sands and clays or plastic silts, respectively, and is limited to a value of 2.2 . Actually, Eq. (32) correlates earthquake magnitude $(M), \mathrm{MSF}$, and $b$. There is an extensive database to account for $b$ parameter in different soils with different densities as illustrated in Figure $14\left(M S F_{\max }\right.$ is a representation of $b$ in Eq. (32)).

$$
M S F_{\max }=1.09+\left(\frac{N_{1,60 c s}}{31.5}\right)^{2} \leq 2.2 \text {. }
$$

The $b$ values recommended by Boulanger and Idriss [36] are more dependent on $M$ in comparison with Kishida and Tsai [35] recommendations. Figure 15 indicates the correlation among MSF, $N_{1,60 c s}$, and $M$ [36].

For loose soil with low penetration resistance compared with denser soils, a flatter MSF diagram is obtained as illustrated in Figure 15. For further information, see Boulanger and Idriss [36]. As the

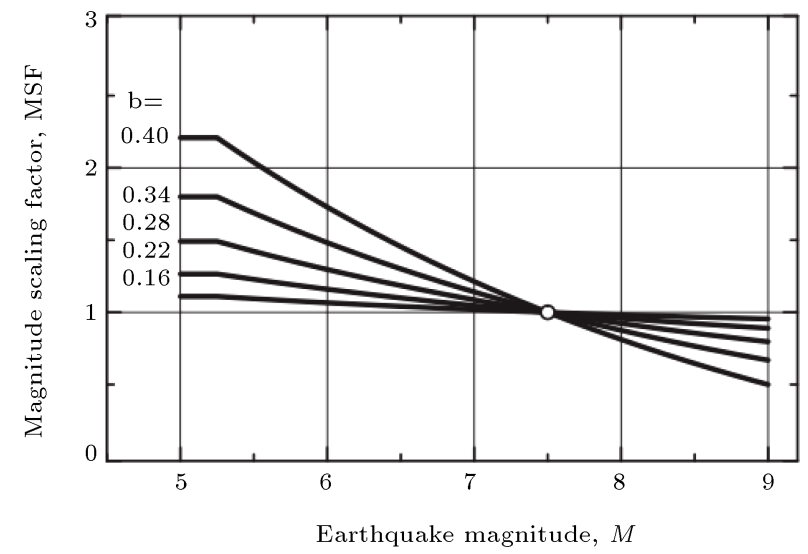

Figure 14. Recommended Magnitude Scaling Factor (MSF) for different values of $b$ and $M$ [36].

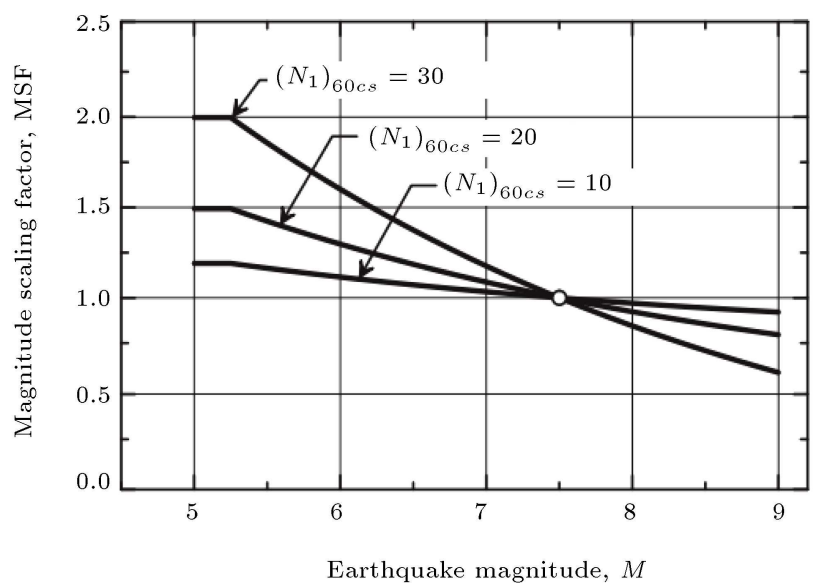

Figure 15. Magnitude Scaling Factor (MSF) for different values of $N_{1,60 c s}$ and $M[36]$.

correlations are empirically attained, the new defined MSF should be applied with the associated value of $r_{d}$, which is dependent on earthquake magnitude (see Section 2.1.7). 


\subsubsection{Non-rigid behavior of soil body against earthquake shear stress $\left(r_{d}\right)$}

Due to the non-rigidity of soil body against earthquake shear stress, the $r_{d}$ parameter is applied. As illustrated in Figure 16, the value of 1 for this parameter indicates rigid behavior [25]. According to NCEER, it was concurred to use the former equations developed by Liao and Whitman [5,39] for this parameter for depths less than 23 meters (Eqs. (34) and (35)) [13,39]; due to the lack of sufficient data, no correlation was determined for deeper levels by 1997 workshop.

$$
\begin{aligned}
& r_{d}=1-0.00765 z \quad \text { for } z \leq 9.15_{m}, \\
& r_{d}=1-0.00765 z \quad \text { for } \quad 9.15_{m}<z \leq 23_{m},
\end{aligned}
$$

where $z$ is the depth in meters.

Idriss (1999) defined $r_{d}$ as a function of depth and earthquake magnitude [40] in the form of a recommendation; In Eqs. (36)-(39), $M$ is the earthquake magnitude and $\alpha(\mathrm{z})$ and $\beta(\mathrm{z})$ are the depth functions. Eq. (36) is developed for depth less than 34 meters and Eq. (39) is developed for deeper levels.

$$
\operatorname{Ln}\left(r_{d}\right)=\alpha(z)+\beta(z) M,
$$

where:

$$
\alpha(z)=-1.012-1.126 \sin \left(\frac{z}{11.73}+5.133\right),
$$

and:

$$
\begin{aligned}
& \beta(z)=0.106+0.118 \sin \left(\frac{z}{11.28}+5.142\right), \\
& r_{d}=0.12 \exp (0.22 M) .
\end{aligned}
$$

Probabilistic studies by Cetin et al. [5] indicate that $r_{d}$ is a function of stratigraphic layers of ground, soil properties, and quake stresses. They also compared the results with the former relations of Liao and Whitman $[5,39]$ and found extensive deviations in the former relationships, which would cause greater values for $r_{d}$. According to their studies, as maximum ground acceleration increases, $r_{d}$ decreases and also $r_{d}$ increases with increasing earthquake magnitude and

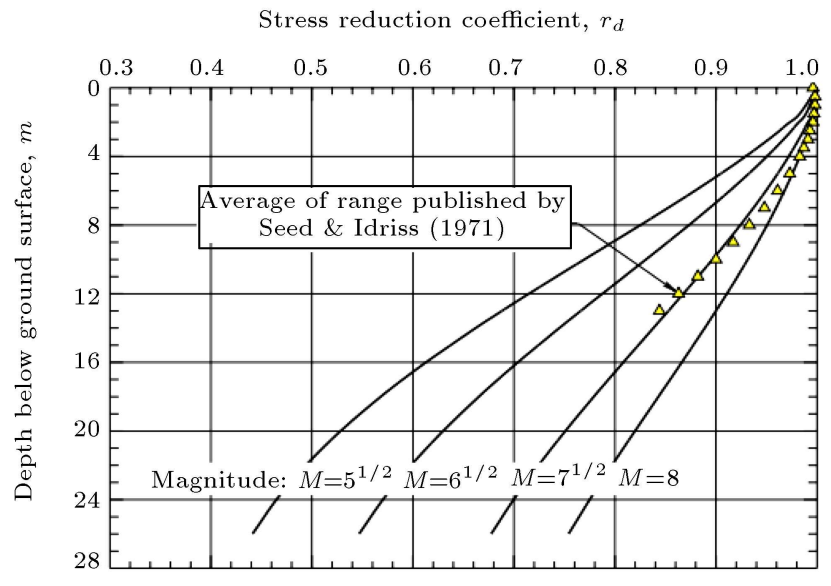

Figure 17. $r_{d}$ curves defined by Idriss (1999) for different values of $M$ in comparison with the defined values by Seed and Idriss [25].

soil stiffness. $r_{d}$ varies with depth linearly in levels deeper than $18 \mathrm{~m}$. This $r_{d}$ is not well-matched with the former simplified procedure of cyclic stress method and should be accompanied with direct dynamic response analysis in determining CSR [5]. For more information, see Cetin et al. [5].

Idriss and Boulanger [25] recommended using Idriss (1999) relationship [40] for $r_{d}$ at a depth less than $20 \mathrm{~m}$; at a higher depth, liquefaction evaluation should be done using direct dynamic response analysis in determining CSR [25]. In Figure 17, obtained $r_{d}$ curves from Idriss (1999) [40] for earthquake magnitudes of $5.5,6.5,7.5$, and 8 are plotted, and the defined $r_{d}$ by Seed and Idriss [4] is compared schematically [25]. The $r_{d}$ defined by Seed and Idriss [4] is convergent with the results of Idriss (1999) [40] at a depth less than $4 \mathrm{~m}$ and an earthquake magnitude of 8 and is also convergent at a depth higher than $8 \mathrm{~m}$ and an earthquake magnitude of 7.5. According to the studies conducted by Idriss and Boulanger [25], the refined correlations for $r_{d}$ are applicable in engineering practice.

\subsection{Correlations between different field tests}

Soil shear resistance against liquefaction is usually obtained by field tests and sometimes by laboratorial
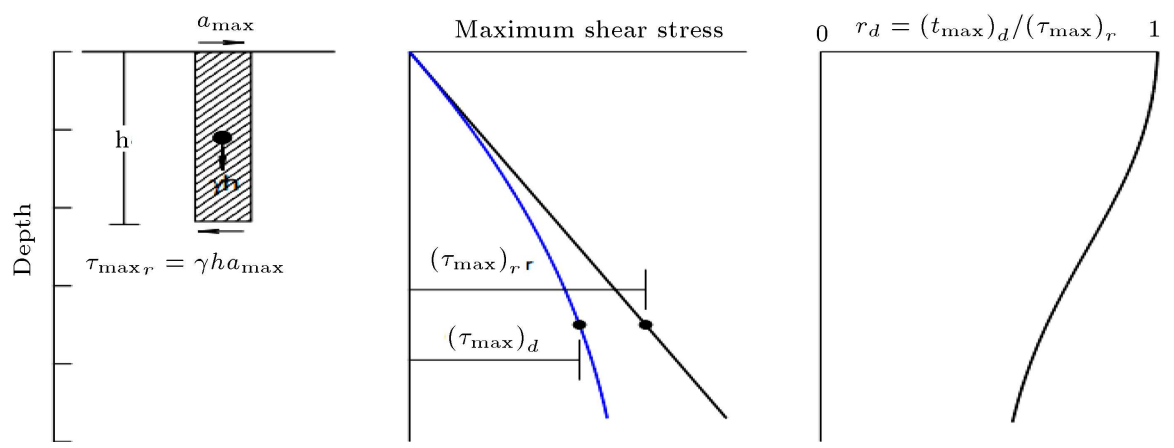

Figure 16. Non-rigid behaviour effect on maximum earthquake shear stress in soil depths. 
Table 3. Comparison of usual field tests [13].

\begin{tabular}{|c|c|c|c|c|}
\hline \multirow[t]{2}{*}{ Feature } & \multicolumn{4}{|c|}{ Test type } \\
\hline & SPT & CPT & $V_{S}$ & BPT \\
\hline $\begin{array}{l}\text { Past measurements } \\
\text { at liquefaction sites }\end{array}$ & Abundant & Abundant & Limited & Sparse \\
\hline $\begin{array}{l}\text { Type of stress-strain } \\
\text { behavior influencing test }\end{array}$ & $\begin{array}{l}\text { Partially drained, } \\
\text { large strain }\end{array}$ & Drained, large strain & Small strain & $\begin{array}{l}\text { Partially drained, } \\
\text { large strain }\end{array}$ \\
\hline $\begin{array}{l}\text { Quality control } \\
\text { and repeatability }\end{array}$ & Poor to good & Very good & Good & Poor \\
\hline $\begin{array}{l}\text { Detection of variability } \\
\text { of soil deposits }\end{array}$ & $\begin{array}{l}\text { Good for closely } \\
\text { spaced tests }\end{array}$ & Very good & Fair & Fair \\
\hline $\begin{array}{l}\text { Soil type in which test } \\
\text { is recommended }\end{array}$ & Nongravel & Nongravel & All & Primarily gravel \\
\hline Soil sample retrieved & Yes & No & No & No \\
\hline $\begin{array}{l}\text { Test measures index or } \\
\text { engineering property }\end{array}$ & Index & Index & Engineering & Index \\
\hline
\end{tabular}

tests. Due to the existence of in-situ stress, high costs of laboratorial tests, and sample disturbance, the field tests are usually preferred [13]. Field investigations could be performed using tests such as SPT, CPT, BPT and shear-wave velocity $\left(V_{s}\right)$. Advantages and disadvantages of each field test have been discussed by many researchers $[5,15,13,22,41,42]$.

Before 1985, due to the insufficient data from CPT tests, the results would be converted to equivalent SPT values. Outspread use of CPT test after 1985 provided sufficient data to infer the relations on the basis of CPT. Given the extensive database and the evaluations and corrections regarding SPT and CPT tests, it is advisable to use them rather than the other field tests [1]. Many design methods are SPT-based, which offer a good recognition of soil properties; CPT test provides a good vision of soil layers for geotechnical engineers and is the most reliable penetration test. On the other hand, BPT is the most unreliable penetration test due to shaft friction [33]; however, shear-wave velocities can be accurately measured in gravels that provide a useful index for evaluating liquefaction resistance. In addition, penetration resistance measured using the Chinese dynamic penetration test has also been found to be an effective and useful measure for the calculation of liquefaction resistance for gravels [43]. NCEEER workshop compared the field tests by the means of past database, stress-strain behavior, re- peatability, precision in detection, applicability, sample retrieval, and output data (Table 3) [13].

Correlations between different field tests were investigated by Andrus et al. [41]. According to 43 data obtained from different regions in California, Southern Carolina, Canada, and Japan, they correlated SPT, CPT, and $V_{s}$ by a probabilistic method in evaluating liquefaction potential. Moreover, Idriss and Boulanger [42] converted the SPT and CPT data regarding the corresponding densities. For more information, see $[41,42]$.

\subsection{Residual shear strength after liquefaction}

As the sand strains beyond the maximum allowable value, the minimum undrained shear strength will be reached; this value remains constant even in higher strains as illustrated by curve 1 in Figure 18. This is

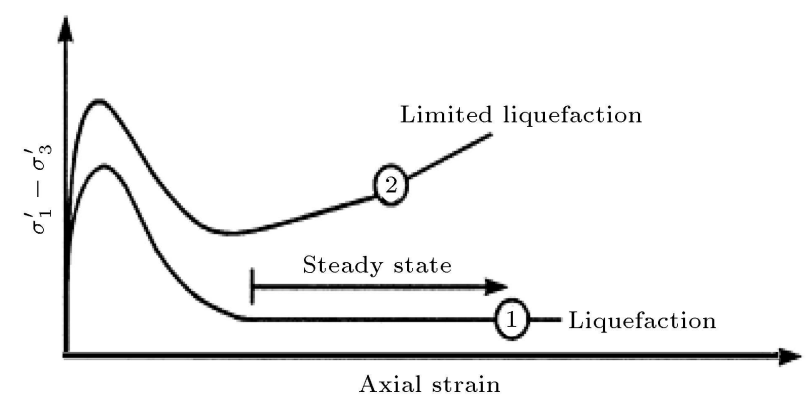

Figure 18. Residual strength after liquefaction [1]. 
called the undrained steady state or residual strength. If the soil recovers its strength after reaching the minimum state, then this is called limited liquefaction or quasi-liquefaction, as illustrated by curve 2 in Figure 18 [1]. Residual strength is mobilized after liquefaction; due to the complications in void redistribution and other reactions in soil, laboratorial reconstitution is not a practical way to evaluate it [42]. Deformation in the liquefied zone is associated with energy dissipation, which can be estimated by numerical models; in addition, residual strength distribution can be represented by means of numerical models [1]. An important issue in geotechnical engineering is determining an appropriate residual strength for soil after liquefaction, which is vital in presenting an economic design for soil improvement.

Seed and Harder [32] correlated $N_{1,60 c s}$ with residual strength $\left(S_{r}\right)$ using inverse analysis (Figure 19). Following Seed and Harder [32], Idriss and Boulanger [42] studied the residual strength in liquefied soil. They correlated $S_{r}$ with $N_{1,60 c s}$ and $\sigma_{v 0}^{\prime}$ in

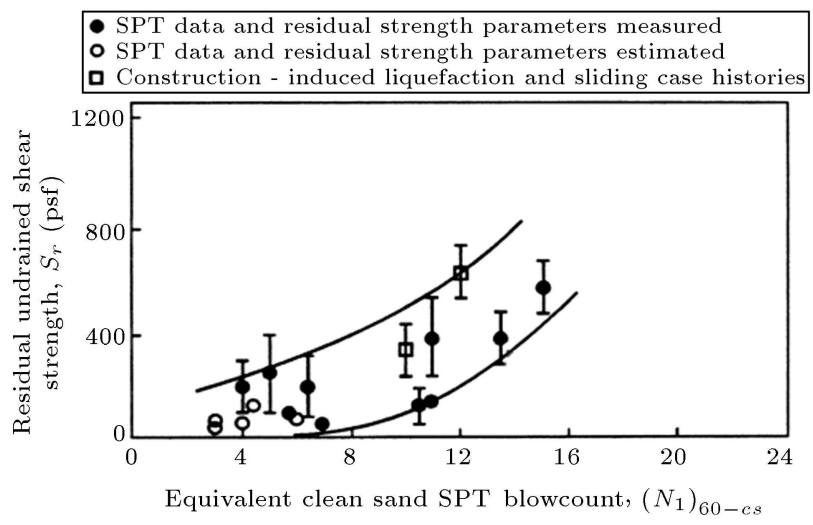

Figure 19. Residual strength for different values of $N_{1,60 c s}[32]$. non-plastic soils by defining a ratio of $S_{r} / \sigma_{v 0}^{\prime}$, which represents the residual strength divided into effective overburden stress; therefore, the parameter of $S_{r} / \sigma_{v 0}^{\prime}$ provides a better definition of soil conditions and void redistribution rather than $S_{r}$. Idriss and Boulanger [42] developed empirical correlations using calibrated SPT blow counts in soil after liquefaction, which is shown by the parameter $N_{1,60 c s-S_{r}}$ (Eq. (40)):

$$
N_{1,60 c s-S_{r}}=N_{1,60}+\Delta N_{1,60-S_{r}} .
$$

The equation is calibrated for fines content by the means of $\Delta N_{1,60-S_{r}}$ in which $\Delta N_{1,60-S_{r}}$ is $1,2,4$, and 5 for fines content of $10 \%, 25 \%, 50 \%$, and $75 \%$, respectively. The recommended curves are shown in Figure 20 [42]. The upper limit in this figure indicates the conditions where void redistribution effect is negligible. In this condition, soil stratigraphy will not resist the dissipation of pore water pressure, and the pore water pressure dissipation is associated with densification in all layers. Eq. (41) shows the upper limit correlation at which undrained shear strength increases with $N_{1,60 c s-S_{r}}$ and, at density of $60 \%$, it reaches a value of $16 \sim 17$. In Figure 20, the lower curve also indicates conditions under which the void redistribution effect is significant; actually, a thick liquefiable layer is underlain by an impermeable layer (Eq. (42)). The equations are limited to $\tan \varphi^{\prime}$, where $\varphi^{\prime}$ is the effective soil friction angle. For $N_{1,60 c s-S_{r}}$ values greater than 14, beyond the available case history data, the curves are plotted as dash-lines.

$$
\begin{aligned}
\frac{S_{r}}{\sigma_{v 0}^{\prime}}= & \exp \left[\frac{N_{1,60 c s-S r}}{16}+\left(\frac{N_{1,60 c s-S r}-16}{21.2}\right)^{3}-3\right] \\
& \leq \tan \varphi^{\prime}
\end{aligned}
$$

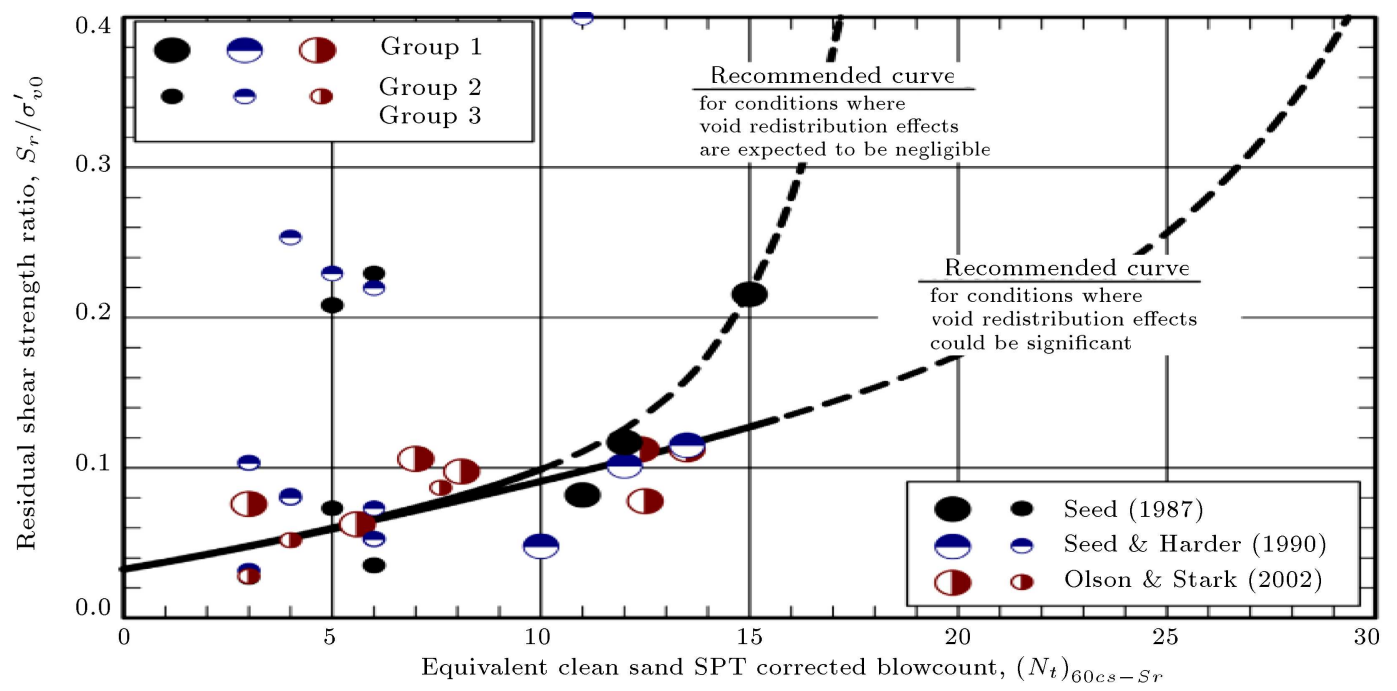

Figure 20. $S_{r} / \sigma_{v 0}^{\prime}$ ratio for different values of $N_{1,60 c s-S_{r}}$ for $\sigma_{v 0}^{\prime}<400 \mathrm{kPa}$ [42]. 


$$
\begin{aligned}
\frac{S_{r}}{\sigma_{v 0}^{\prime}}= & \exp \left[\frac{N_{1,60 c s-S_{r}}}{16}+\left(\frac{N_{1,60 c s-S_{r}-16}}{21.2}\right)^{3}-3\right] \\
& \times\left[1+\exp \left(\frac{N_{1,60 c s-S_{r}}}{2.4}-6.6\right)\right] \leq \tan \varphi^{\prime} .
\end{aligned}
$$

Continuing the efforts made by Idriss and Boulanger [42], Kim et al. [44] tried to correlate the volume strain of silty soils containing non-plastic fines with post-liquefaction minimum void ratio, which was obtained by laboratorial simulations using a self-made automatic tamping machine [44]. They found that the post-liquefaction minimum void ratio was not largely affected by initial density and effective stress of soil. On the contrary, based on centrifuge models, Dewoolkar et al. [45] concluded that the residual strength and probably the strain rate were highly increased by increasing the relative density.

Ishihara et al. [46] declared that the volume change in soil was significantly dependent on the degree of disturbance induced by undrained cyclic loading; they also introduced a method to determine the postliquefaction minimum void ratio. Additional loading applied after reaching the residual strength was found to be effective in post-liquefaction behavior and residual volumetric strain of soils based on laboratorial tests [47]. The timing of liquefaction was considered effective in predicting soil deformations, whether it happens early or late in an earthquake [48]. By determining the timing of liquefaction, the later cyclic loadings after liquefaction are recognizable. Consequently, a method was presented to predict the soil deformations induced by the later loadings in a particular ground motion [48].

\section{Discussions}

The recent studies have clearly notified that the new generation of liquefaction assessment has begun, which concentrates on post-liquefaction characteristics of soils to present a risk analysis. Inconsistency and ambiguity in recent conclusions emphasize the necessity of a more precise and comprehensive study to reach a common sense in defining the characteristics of liquefied soil.

Risk analysis is a relatively new feature in engineering, which should be informed and emphasized by experts. Risk management in safety analysis of dams has been described by Canadian Standard Association (CSA [49]) as a guideline. As is noted by CSA, after selecting the expected level of seismic hazard, stability calculation based on limit equilibrium is performed. On the basis of probabilistic relationships, different levels of consequences based on seismic hazard zoning are defined. The most important issue in this method is the definition of different levels of performances and the probable consequences for each level, which should be defined by experts.

On the basis of a fuzzy multi-criteria approach, seismic hazard in different regions of Iran was assessed by determining the most effective factors of vulnerability and the most vulnerable regions in seismic areas [50]. Vulnerability is an ambiguous definition that should be clarified regarding the different effective factors [50]. According to their study, seismic ground coefficient and population in a given region are the most effective vulnerability factors that should be noticed in organizing a risk management.

Risk management analysis against liquefaction has been performed in previous studies. Baker and Faber [51] zoned a region in Adapazari in Turkey to assess the liquefaction potential by applying probabilistic seismic hazard analysis and using geostatistics software of ArcGIS.

Studies made by Pacific Earthquake Engineering Research center in 2003 resulted in charts including all possible seismic levels in evaluating liquefaction potential. The corresponding risk for these levels could be defined as fatality, economic loss, region importance, etc. According to this approach, Kramer and Mayfield [52] plotted a number of curves that would represent the required SPT-N for safety factors of $1,1.2$, and 1.5 at different depths of ground for a return period of 475 years (Figure 21). Figure 22 also shows the required SPT-N for different values of Factor of Safety (FS) against liquefaction and different levels of quakes (different return periods).

In spite of the efforts made, the studies show that there is still a defect in correlations in introducing a reliable performance-based soil improvement. The identified gap in this review creates an opportunity for future investigators to initiate research in order to expand the residual strength definition and correlate it with required SPT-N defined for different levels of quakes. Correlating residual strength with the required SPT-N can reduce the calculation errors in predictions resulting from void redistribution after liquefaction. The future efforts can be made to obtain more reliable correlations to perform soil improvements on the basis of performance and vulnerability of regions. Empirical case histories for residual strength after liquefaction have made the possibility of developing an economic design for soil improvement to confront the liquefaction hazards.

\section{Summary and conclusions}

A comprehensive overview of literature on the liquefaction potential evaluation, considering deterministic approach using Standard Penetration Test (SPT) field test records prior to 2017 , was presented. The objectives are to: 


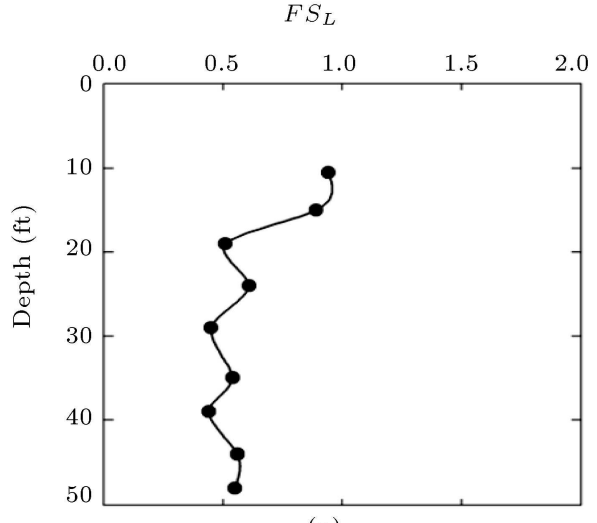

(a)

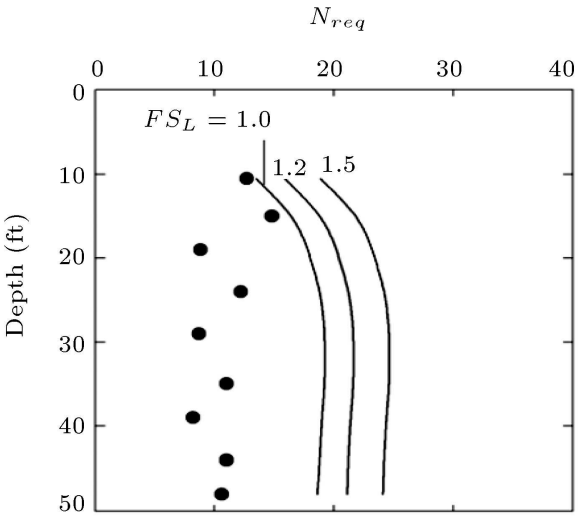

(b)

Figure 21. Considering a return period of 475 years: (a) Variation of Factor of Safety (FS) with depth and (b) $N_{r e q}$ for safety factors of $1,1.2$, and $1.5[52]$.

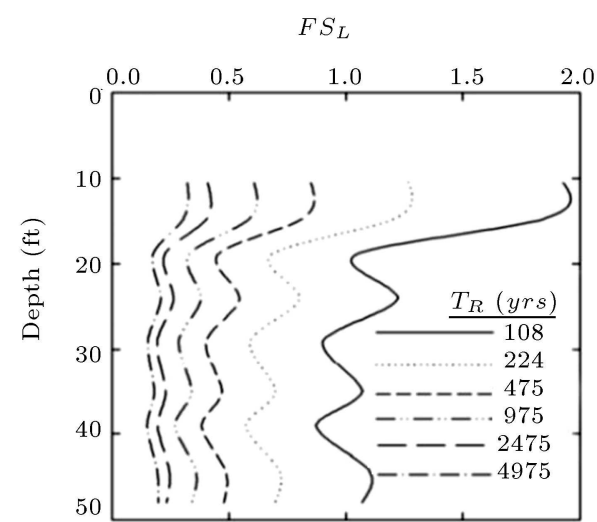

(a)

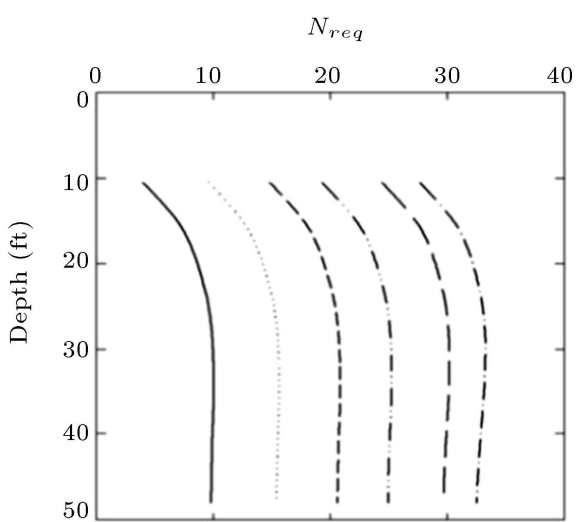

(b)

Figure 22. (a) Factor of Safety (FS) against liquefaction for different return periods. (b) $N_{r e q}$ for different values of FS and return periods [52].

1. Connect different methods in deterministic approach;

2. Facilitate reviewing the development of correlations;

3. Assess both the cyclic stress liquefaction and the flow liquefaction in a unified system;

4. Identify the main sources as a database for the future investigators.

Some of the major issues discussed in this paper include:

- Earthquake-induced liquefaction occurred on natural slopes and overburdened grounds in Chi-Chi (1999) in Taiwan and Adapazari (1999) in Turkey were discussed. According to the studies, if the soil be subjected to static shear stress and cyclic stress simultaneously, an upward pore water pressure will annihilate the contact and cohesive resistance of the soil and, therefore, even a plastic silty soil will gradually liquefy;

- Recent developments after the 1997 workshop in deterministic approach correlations and cyclic stress method were reviewed. The recent corrections of the SPT calibration coefficients, fines content, and the controversial parameters of $K_{\sigma}, K_{\alpha}, r_{d}$, and MSF were discussed. Moreover, Cyclic Stress Ratio (CSR) equations and relationships between different field tests were mentioned;

- Use of corresponding $r_{d}$ and MSF in correlations was accentuated. Regarding the new approach, the parameters of $r_{d}$ and MSF were dependent on earthquake magnitude simultaneously. Consequently, the corresponding MSF and $r_{d}$ should be applied in deterministic approach correlations. In addition, the new MSF was found dependent on soil characteristics;

- Residual shear strength was adverted in this study. New developments in residual shear strength equations have led to the possibility of developing an economic design for soil improvement.

The absence of a performance-based soil improvement is crucially realized, which may be defined based on the required SPT-N for different return periods of quakes and the latest definition of residual strength. 


\section{Acknowledgment}

We would like to show our gratitude to Dr. Hamed Bayesteh, the Assistant Professor of Civil Engineering in Qom University, for comments and useful suggestions that have greatly improved the manuscript.

\section{References}

1. Finn, W.D.L. "State of the art geotechnical earthquake engineering practice", Soil Dynamics and Earthquake Engineering, 20, pp. 1-15 (2000).

2. Das, B.M. and Ramana, G.V., Principles of Soil Dynamics, Second Edition, CENGAGE Learning Publication, ISBN-13: 978-0-495-41134-5 (2010).

3. Bray, J.D. and Macedo, J. "6th Ishihara lecture: Simplified procedure for estimating liquefaction-induced building settlement", Soil Dynamics and Earthquake Engineering, 102, pp. 215-231 (2017).

4. Seed, H.B. and Idriss, I.M. "Simplified procedure for evaluating soil liquefaction potential", Journal of the Soil Mechanics and Foundation Division, 97(SM9), Proc. Paper 8371, pp. 1249-1273 (1971).

5. Cetin, K.O., Seed, R.B., Kiureghian, A.D., Tokimatsu, K., Harder, L.F., Kayen, R.E., and Moss, E.S. "Standard penetration test-based probabilistic and deterministic assessment of seismic soil liquefaction potential", Geotechnical and Geoenvironmental Engineering, 130(12), pp. 1314-1340 (2004).

6. Seed, H.B. and Idriss, I.M., Ground Motion and Soil Liquefaction During Earthquakes, Earthquake Engineering Research Institute, Oakland, Ca (1982).

7. Andrews, D.C.A. and Martin, G.R. "Criteria for liquefaction of silty soils", 12th World Conference on Earthquake Engineering, Proceedings, Auckland, New Zealand (2000).

8. Bray, J.D., Sancio, R.B., Durgunoglu, T., Onalp, A., Seed, R.B., Stewart, J.P., Youd, T.L., Baturay, M.L., Cetin, K.O., Christensen, C., Karadayilar, T., and Emrem, C. "Ground failure in Adapazari, Turkey. Proceedings of earthquake geotechnical engineering satellite conference of the XVth", International Conference on Soil Mechanics and Geotechnical Engineering, Istanbul, Turkey, August 24-25 (2001).

9. Sancio, R.B., Bray, J.D., Stewart, J.P., Youd, T.L., Durgunoglu, H.T., Onalp, A., Seed, R.B., Christensen, C., Baturay, M.B., and Karadayilar, T. "Correlation between ground failure and soil conditions in Adapazari, Turkey", Soil Dynamics and Earthquake Engineering, 22, pp. 1093-1102 (2002).

10. Chu, D.B., Stewart, J.P., Lee, S., Tsai, J.S., Lin, P.S., Chu, L.B., Seed, R.B., Hsu, S.C., Yu, M.S., and Wang, M.C. "Documentation of soil conditions at liquefaction and non-liquefaction sites from 1999 Chi-Chi (Taiwan) earthquake", Soil Dynamics and Earthquake Engineering, 24, pp. 647-657 (2004).
11. Chang, M., Kuo, C.P., Shau, S.H., and Hsu, R.E. "Comparison of SPT-N-based analysis methods in evaluation of liquefaction potential during the 1999 Chi-Chi earthquake in Taiwan", Computers and Geotechnics, 38, pp. 393-406 (2011).

12. Tokimatsu, K., and Yoshimi, Y. "Empirical correlation of soil liquefaction based on SPT-N values and fines content", Soils and Foundations, 23(4), pp. 56-74 (1983).

13. Youd, T.L., Idriss, I.M., Andrus, R.D., et al. "Liquefaction resistance of soils: Summary report from the 1996 NCEER and 1998 NCEER/NSF workshops on evaluation liquefaction resistance of soils", Geotechnical and Geoenvironmental Engineering, 127(4) pp. 297-313 (1998).

14. Japan Rail Association (JRA) "Design code and explanations for roadway bridges", Part V, Seismic Resistance Design, Japan (1996).

15. Seed, R.B., Cetin, K.O., Moss, R.E.S., Kammerer, A.M., Wu, J., Pestana, J.M., Riemer, M.F., Sancio, R.B., Bray, J.D., Kayen, R.E., and Faris, A. "Recent advances in soil liquefaction engineering: A unified and consistent framework", 26th Annual ASCE Los Angeles Geotechnical Spring Seminar, Keynote Presentation, HMS. Queen Mary, Long Beach, California, Berkeley, Earthquake Engineering Research Center (EERC) (2003).

16. Sato, H., Nhan, T.T., and Matsuda, H. "Earthquake induced settlement of a clay layer", Soil Dynamics and Earthquake Engineering, 104, pp. 418-431 (2018).

17. Casagrande, A. "The structure of clay and its importance in foundation engineering", Contribution to Soil Mechanics, 1925-1940, Boston Society of Civil Engineering, pp. 257-276 (1932).

18. Castro, G. "Liquefaction of sands", Harvard Soil Mechanics Series, 81, Harvard University, Cambridge, MA (1969).

19. Ishihara, K. "Liquefaction and flow failure during earthquakes: Thirty-third rankine lecture", Geotechnique, 43(3), pp. 351-415 (1993).

20. Robertson, P.K. and Wride, C.E. "Evaluating cyclic liquefaction potential using the cone penetration test", Canadian Geotechnical Journal, 35(3), pp. 442-459 (1998).

21. Javanmardi, Y., Imam, S.M.R., Pastor, M., and Manzanal, D. "A reference state curve to define the state of soils over a wide range of pressures and densities", Geotechnique, 68(2), pp. 95-106 (2018).

22. Andrus, R.D. and Stokoe, K.H. "Liquefaction resistance based on shear wave velocity", NCEER Workshop on Evaluation of Liquefaction Resistance of Soils, NCEER-97-0022 (1997). 
23. Hynes, M.E., Olsen, R., and Yule, D.E. "Influence of confining stress on liquefaction resistance", Proc, International Symposium on the Physics and Mechanics of Liquefaction, Balkema, pp. 145-152 (1998).

24. Bay, J.A. and Cox, B.R. "Shear wave velocity profiling and liquefaction assessment of sites shaken by the 1999 Kocaeli", Turkey Earthquake, PEER project SA301718336 (2001).

25. Idriss, I.M. and Boulanger, R.W. "Semi-empirical procedures for evaluating liquefaction potential during earthquakes", Soil Dynamics and Earthquake Engineering, 26, pp. 115-130 (2006).

26. Boulanger, R.W. "High overburden stress effects in liquefaction analysis", Geotechnical and Geoenvironmental Engineering, 129(12), pp. 1071-1082 (2003).

27. Boulanger, R.W. and Idriss, I.M. "State normalization of penetration resistance and the effect of overburden stress on liquefaction resistance", 11th International Conference on Soil Dynamics and Earthquake Geotechnical Engineering, University of California, Berkeley, CA (2004).

28. Seed, H.B., Tokimatsu, K., Harder, L.F., and Chung, R.M. "The influence of SPT procedures in soil liquefaction resistance evaluations", Journal of Geotechnical Engineering, ASCE, 111(12), pp. 1425-1445 (1985).

29. Gratchev, I.B., Sassa, K., Osipov, V.I., and Sokolov, V.N. "The liquefaction of clayey soils under cyclic loading", Engineering Geology, 86, pp. 70-84 (2006).

30. Idriss, I.M. and Boulanger, R.W. "Evaluating of cyclic softening in silts and clays", Geotechnical and Geoenvironmental Engineering, 133(6), pp. 641-652 (2015).

31. Seed, H.B. "Earthquake-resistance design of earth dams", Proc., Symp. Seismic Design of Earth Dams and Caverns, ASCE, New York, pp. 41-64 (1983).

32. Seed, H.B. and Harder, L.F. "SPT-based analysis of cyclic pore pressure generation and undrained residual strength", Proceedings, Seed Memorial Symposium, Vancouver, BiTech Publishers, pp. 351-376 (1990).

33. Finn, W.D.L. "State of the art for the evaluation of seismic liquefaction potential", Computers and Geotechnics, 29, pp. 329-341 (2002).

34. Boulanger, R.W. and Idriss, I.M. "Evaluation of cyclic softening in silts and clays", Geotechnical and Geoenvironmental Engineering, 33(6), pp. 641-652 (2007).

35. Kishida, T. and Tsai, C. "Seismic demand of the liquefaction potential with equivalent number of cycles for probabilistic seismic hazard analysis", Geotechnical and Geoenvironmental Engineering, 140(3), 04013023 (2014). DOI: 10.1061/(ASCE)GT.1943-5606.0001033

36. Boulanger, R.W. and Idriss, I.M. "Magnitude scaling factors in liquefaction triggering procedures", Soil Dynamics and Earthquake Engineering, 79, pp. 296303 (2015). DOI: 10.1016/j.soildyn.2015.01.004
37. Idriss, I.M. and Boulanger, R.W., Soil Liquefaction During Earthquakes, EERI Publication, Monograph MNO-12 Earthquake Engineering Research Institute, Oakland (2008).

38. Kondoh, M., Sasaki, Y., and Matsumoto, H. "Effect of fines contents on soil liquefaction strength (Part 1)", Proceedings of the Annual Meeting of the Japanese Society of Soil Mechanics and Foundation Engineering, Public Works Research Institute, Ministry of Construction, Tsukuba, Japan (1987).

39. Liao, S.S.C. and Whitman, R.V. "Overburden correction factor for SPT in sand", Journal of Geotechnical Engineering, 112(4), pp. 373-377 (1986).

40. Idriss, I.M. "An update to the Seed-Idriss simplified procedure for evaluating liquefaction potential", Proceedings of TRB Workshop on New Approaches to Liquefaction, Publication No. FHWA-RD-99-165, Federal Highway Administration, Washington DC (1999).

41. Andrus, R.D., Piratheepan, P., Ellis, B.S., Zhang, J., and Juang, C.H. "Comparing liquefaction evaluation methods using penetration-Vs relationships", Soil Dynamics and Earthquake Engineering, 24, pp. 713-721 (2004).

42. Idriss, I.M. and Boulanger, R.W. "SPT- and CPTbased relationships for the residual shear strength of liquefied soils", Soil Dynamics and Earthquake Engineering, 68, pp. 57-68 (2014).

43. Cao, Z., Youd, T.L., and Yuan, X. "Chinese dynamic penetration test for liquefaction evaluation in gravelly soils", Geotechnical and Geoenvironmental Engineering, 139(8), pp. 1320-1333 (2013).

44. Kim, J., Kawai, T., Kazama, M., and Mori, T. "Density index for estimating the postliquefaction volumetric strain of silty soils", International Journal of Geomechanics, 16(5), C4015005 (2016). DOI: 10.1061/(ASCE)GM.1943-5622.0000574

45. Dewoolkar, M., Hargy, J., Anderson, I., Alba, P.D., and Olson, S.M. "Residual and postliquefaction strength of a liquefiable sand", Journal of Geotechnical and Geoenvironmental Engineering, 142(2), 04015068 (2015). DOI: 10.1061/(ASCE)GT.1943-5606.0001374

46. Ishihara, K., Harada, K., Lee, W.F., Chan, C.C., and Safiullah, A.M.M. "Post-liquefaction settlement analysis based on the volume change characteristics of undisturbed and reconstituted samples", Soils and Foundations, 56(3), pp. 533-546 (2016).

47. Kim, J., Kawai, T., and Kazama, M. "Laboratory testing procedure to assess post-liquefaction deformation potential", Soils and Foundation, 57, pp. 905-919 (2017).

48. Kramer, S.L., Sideras, S.S., and Greenfield, M.W. "The timing of liquefaction and its utility in liquefaction hazard evaluation", Soil Dynamics and Earthquake Engineering, 91(C), pp. 133-146 (2016). DOI: 10.1016/j.soildyn.2016.07.025 
49. CSA (Canadian Standard Association), Risk Management: Guideline for Decision-Makers (CAN/CSAQ850-97), Rexdale, Ontario: Canadian Standard Association (1997).

50. Vahdat, K., Smith, N.J., and Amiri, G.G. "Fuzzy multicriteria for developing a risk management system in seismically prone area", Socia-Economic Planning Sciences, 48, pp. 235-248 (2014).

51. Baker, J.W. and Faber, M.H. "Liquefaction risk assessment using geostatistics to account for soil special variability", Geotechnical and Geoenvironmental Engineering, 134(1), pp. 14-23 (2008).

52. Kramer, S.L. and Mayfield, R.T. "Performance-based liquefaction hazard evaluation", Earthquake Engineering and Soil Dynamics, Geo-Frontiers Congress, January 24-26, Austin, Texas, United States (2005). DOI: $10.1061 / 40779(158) 21$

\section{Biographies}

Ehsan Ghorbani received his BS and MSc degrees from Imam Khomeini International University of Qazvin (IKIU) and University of Qom, respectively. He is currently the supervisor and an execution assistant in the Soil Improvement Services Co. His research areas lie in soil improvement, natural hazards, excavation, monitoring, and numerical modeling.

Ali M. Rajabi received his BS, MSc, and $\mathrm{PhD}$ degrees from Ferdowsi Mashhad, Bu-Ali Sina Hamedan, and Tarbiat Modares Universities, respectively. He is currently an Assistant Professor at University of Tehran, Iran. His research areas lie in engineering geology, soil improvement, environmental geotechnics, natural hazard, and material properties. 